\title{
Original Article \\ Demographic Profile of Spinal Cord Injury Patients Admitted in a Rehabilitation Center: An Observational Study from Bangladesh
}

\author{
Ziniya Mustary Rahman'1, S. M. Lftekhar Alam², Md. Shujayt Gani ${ }^{3}$, Faruq Ahmed4, \\ A. K. M. Minarul Tawhid ${ }^{5}$, Md. Shahoriar Ahmed ${ }^{6}$ \\ ${ }^{1}$ Physiotherapy Department, Centre for the rehabilitation of the Paralysed (CRP), ${ }^{2}$ CIVIC Trial Project, Centre \\ for the rehabilitation of the Paralysed (CRP), ${ }^{3}$ Physiotherapy Department, Centre for the rehabilitation of \\ the Paralysed (CRP), ${ }^{4} \mathrm{CIVIC}$ Trial Project, Centre for the rehabilitation of the Paralysed (CRP), ${ }^{5}$ Physiotherapy \\ Department, Proyash, Dhaka, Bangladesh, ${ }^{6}$ Executive Officer, Bangladesh Physiotherapy Association (BPA). \\ Address for correspondence: Md. Shahoriar Ahmed, Executive Officer, Bangladesh Physiotherapy \\ Association (BPA), Bangladesh. Phone: 01794859401. E-mail: physio.shahoriar@gmail.com
}

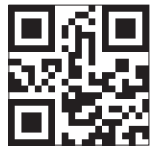

Quick Access Code

How to cite this article: Rahman ZM, Iftekhar SM, Gani MS, Ahmed F, Tawhid AKMM, Ahmed MS. Demographic Profile of Spinal Cord Injury Patients Admitted in a Rehabilitation Center: An Observational Study from Bangladesh. Journal of Medical Research and Innovation. 2018;2(2):e000111.

DOI: 10.15419/jmri.111

Publication history: Received: 04-02-2018 Accepted: 01-03-2018 Published: 01-03-2018

Editor: Dr. Varshil Mehta

Copyright: Rahman ZM. This is an open access article distributed under the terms of the Creative Commons Attribution License CC-BY 4.0., which permits unrestricted use, distribution, and reproduction in any medium, provided the original author and source are credited.

Funding: NIL

Conflict of Interest: NIL

\begin{abstract}
Background: Spinal cord injury $(\mathrm{SCl})$ is a life-threating condition which has a profound impact in the morbidity and mortality. SCl causes lifetime sufferings and mostly occurs among the young adults. Not only in Bangladesh but also worldwide, $\mathrm{SCl}$ is a devastating and burdensome condition. This research was conducted to see the demographic profile of $\mathrm{SCl}$ patients in Bangladesh. Methods: This is a retrospective analysis where data were collected from medical records of all SCI patients admitted in between January 2012 and December 2014 from Center for the Rehabilitation of the Paralysed, Savar. Results: A total of $1172 \mathrm{SCl}$ patients were analyzed. Most of the patients were in their second and third decades of life which consisted $28.8 \%(n=338)$. Among total respondents, $86.2 \%(n=1010)$ were male and $13.8 \%(n=162)$ were female. Most of the participants, $61.1 \%(n=716)$, were from rural area. The main cause of $\mathrm{SCl}$ was fall from height (FFH) $\{45.8 \%(n=537)\}$ followed by the road traffic accidents (RTA) $\{24.7 \%(n=288)\}$. Overall, $52.3 \%(n=613)$ of participants suffered from traumatic paraplegia while $60.9 \%(n=714)$ had complete lesion. Among the total participants, $30.70 \%(n=359)$ of participants had skeletal level C1-C7 injury. Division-wise distribution shows that FFH is a major cause of SCl $\{14.84 \%$ (n $=174)$ \} followed by the RTA which is a second most common cause in $8.95 \%(n=105)$ of participants in Dhaka division while $\mathrm{SCl}$ due to bull attacks and bullet injury are a major cause in Khulna division $\{1.02 \%$ $(n=12)\}$ and Chittagong division respectively. Conclusion: The data are collected from a tertiary level of rehabilitation center where extensive demographic data were not previously represented. In many developing countries, $\mathrm{SCl}$ is neglected, poorly managed, and deprived from society. In addition, the present study suggests that demographic factors may affect the characteristics of $\mathrm{SCl}$.
\end{abstract}

Keywords: Bangladesh, cause of injury, Centre for the Rehabilitation of the Paralysed, demography, Savar, spinal cord injury

\section{Introduction}

In South-Asia region, Bangladesh is a developing country, with a burden of a large population which is about 160 million. ${ }^{[1-3]}$ Population growth rate of Bangladesh per year was $1.59 \%$ which includes $27 \%$ in urban area and $73 \%$ in rural. Bangladesh is a densely over populated country where literacy rate of about $61.0 \%$ among the age of 15 years and above. ${ }^{[4,5]}$ Not only in Bangladesh but also worldwide, spinal cord injury $(\mathrm{SCl})$ is a devastating and burdensome life-threating condition which has a profound impact on the morbidity and mortality. ${ }^{[1,6,7]} \mathrm{SCl}$ affects mostly young-and middle-age adults, and recovery depends on the type and severity of lesion, rehabilitation time, and individual performance how effectively he/she completes every day task. ${ }^{[8,9]}$ Globally, a trend has been observed that most of the traumatic spinal cord injuries 
occurred by fall from height (FFH) or either road traffic accident (RTA). ${ }^{[1,3,5]} \mathrm{SCl}$ from traumatic or non-traumatic both has a profound impact on many factors such as physical, mental, domestic, and social life of an individual. ${ }^{[1,5]}$ There are different types of secondary complications usually suffered by spinal cord injured patients, among them, pressure sore, urinary complications, sexual dysfunctions, and bowel bladder problems are main, among them some are preventable and some are need re-hospitalization, and eventually, it leads to a great deal of disability, morbidity, degree of dependence, and mortality. ${ }^{[5]}$ Different study has been conducted in developing and developed country to find the cause and characteristics of $\mathrm{SCl}$, and it seems that it depends on geographic area and socioeconomic status. Life expectancy after $\mathrm{SCl}$ is markedly reduced due to secondary complication, severity of injury, social deprivation, and lack of proper rehabilitation ${ }^{[6,7]}$ Evidence from 2011, Cripps et al. showed that global prevalence of SCl was 236 and 1009 per million which was similar to a result found in 1995 by Blumer and Quine (about 110-1120 per million of population). ${ }^{[10]}$ The current study was aimed to look into the demographic profile of $\mathrm{SCl}$ patients and also try to find the impact factor of the cause of injury in different division of Bangladesh which will help us to identify the etiology, risk factor, and preventive measure.

\section{Materials and Methods}

\section{Ethical considerations}

Formal permission was taken from the Physiotherapy Department of Bangladesh Health Professions Institute as it was an academic institute of Centre for the Rehabilitation of the Paralysed (CRP). At the beginning of data collection, permission was obtained from the concerned authorities ensuring the safety of the participants. All information was kept in secure. Confidentiality of the person and the information was maintained and observed, and unauthorized persons did not have any access to the collected data.

\section{Data collection}

Data were collected from all admitted patients to the CRP in between January 2012 and December 2014. Patient with complete information is included in this study. Patients with incomplete information and those who are discharge on request bond (DORB) are excluded from the study. Data that were recorded consisted of age, sex, mode of injury, diagnosis, skeletal level, and American Spinal Injury Association (ASIA) Impairment Scale (AIS). ${ }^{[11]}$ Recovery was categorized as a complete and incomplete lesion. Etiology of injury was categorized into different groups such as FFH, RTA, and heavy object fall over head/back, which are the leading cause and shallow diving water, scarf injury, bull attack, and physical assault are the diverse cause. Non-traumatic causes such as tuberculosis of spine (TB) and transverse myelitis are associated causes of spinal cord injuries.

\section{Setting and participants}

In Bangladesh, there are very few spinal injury centers. Among them, CRP is recognized as the tertiary level of spinal injury center, it receives all types of spinal injury patients either directly, through referral, after surgery for rehabilitation, or admitted with complex secondary complication such as pressure ulcer. CRP is a well-known not for profit organization ${ }^{[7,12]}$ in Bangladesh for rehabilitation of the $\mathrm{SCl}$ patients. As a mother organization, CRP receives referrals from different hospitals and from all over Bangladesh for rehabilitation of the $\mathrm{SCl}$ patients. CRP provides acute care for $\mathrm{SCl}$ patients and admits approximately $390 \mathrm{SCl}$ patients in each year. ${ }^{[12]}$ In CRP, patients pay very small amount as their income source ability but care is primarily funded by the government and not-for-profit organizations.

\section{Analysis}

After managing data properly, it was analyzed in the Statistical Package of Social Science 16 version and Microsoft Excel Software 2007 version.

\section{Results}

Among 1172 respondents, most of the patients were in their second and third decades of age which consisted $28.8 \%$ ( $n=338)$, followed by $24.5 \%(n=287)$ in between 31 and 40 years and $17.8 \%(n=209)$ in between 41 and 50 . In this study, $86.2 \%$ ( $n=1010)$ were male and $13.8 \%(n=162)$ were female. Of 716 respondents, $61.1 \%$ were from rural areas and 456 were from urban areas (38.9\%) [Table 1].

Of 1172 respondents, $52.3 \%(n=613)$ had the diagnosis of traumatic paraplegia (TP) and $43.5 \%(n=510)$ had traumatic tetraplegia (TT), whereas non-TP and non-TT were the other diagnosis having the distribution of $3.3 \%$ (39) and $0.9 \%$ (10), respectively [Table 2].

537 participants $(45.8 \%)$ had fallen from the height (FFH), and RTA was the second common cause having the distribution of 288 patients (24.7\%). 112 (9.6\%) gave a history of fall of object overhead and back was 106 (9\%). Spinal TB was observed in $38(3.2 \%)$, while bull attacks and physical assault were seen in $24(2 \%)$ and $23(2 \%)$ patients respectively. Interestingly, scarf injury and shallow diving water were observed in 13 (1.1\%) and 11 (0.9\%) patients respectively [Table 3].

According to this assessment, Table 4 shows that FFH is the leading cause of $\mathrm{SCl}$, and $\mathrm{FOH}$ was the second most common cause according to the 1995-2009 assessments, but after 2009, FFH is the leading cause of SCl, and RTA was the second most common cause for $\mathrm{SCl}$ in Bangladesh [Table 4].

Regarding the extent of injury, 60.9\% ( $n=714)$ of participants had complete lesion on admission, whereas $53.2 \%(n=624)$ on discharge that are Category A in ASIA scale. Categories B, C, 
D, and $E$ had the distribution of $19.6 \%, 11.3 \%, 7.3 \%$, and. $8 \%$ on admission and $12.5 \%, 13 \%, 19.2 \%$, and $2.1 \%$ on discharge, respectively [Table 5].

Table 1: Distribution of demographic variables of the respondents $(n=1172)$

\section{Demographic Variable}

$\begin{array}{lc}\text { Age (years) } & 15(1.3) \\ 0-10 & 187(16.0) \\ 11-20 & 338(28.8) \\ 21-30 & 287(24.5) \\ 31-40 & 209(17.8) \\ 41-50 & 98(8.4) \\ 51-60 & 28(2.4) \\ 61-70 & 10(0.9) \\ 71-80 & \\ \text { Gender } & 1010(86.2) \\ \text { Male } & 162(13.8) \\ \text { Female } & \\ \text { Living area } & 716(61.1) \\ \text { Rural } & 456(38.9) \\ \text { Urban } & \end{array}$

Table 2: Distribution of diagnoses of spinal cord injury among the respondents $(n=1172)$

\section{Diagnosis}

Frequency (\%)

$\begin{array}{lc}\text { TP } & 613(52.3) \\ \text { TT } & 510(43.5) \\ \text { NTP } & 39(3.3) \\ \text { NTT } & 10(0.9)\end{array}$

TP: Traumatic paraplegia, TT: Traumatic tetraplegia, NTP: Non-traumatic paraplegia, NTT: Non-traumatic tetraplegia

Table 3: Distribution of cause of spinal cord injury among the respondents $(n=1172)$

\begin{tabular}{lc} 
Cause of injury & Frequency (\%) \\
Fall from height & $537(45.8)$ \\
Road traffic accident & $288(24.7)$ \\
Fall heavy object over head & $112(9.6)$ \\
Fall heavy object over the back & $106(9.0)$ \\
Spinal tuberculosis & $38(3.2)$ \\
Bull attack & $24(2.0)$ \\
Physical assault & $23(2.0)$ \\
Scarf injury & $13(1.1)$ \\
Shallow water diving & $11(0.9)$ \\
Transverse myelitis & $11(0.9)$ \\
Bullet injury & $8(0.7)$ \\
Sports injury & $1(0.1)$ \\
\hline
\end{tabular}

FFH: Fall from height, RTA: Road traffic accident, TM: Transverse myelitis
Among the 1172 participants, $30.70 \%(n=359)$ had skeletal level C1-C7, 30.10\% ( $n=353)$ had skeletal level T1-T12, $22.10 \%$ $(n=259)$ had skeletal level L1-L5, and $17.10 \%(n=201)$ had no impression was seen in magnetic resonance imaging and X-ray view [Figure 1].

Figure 2 depicts the geographical location of persons with $\mathrm{SCl}$ in the study. A total of $38.9 \%$ (456) of the persons with $\mathrm{SCl}$ were from the urban areas, whereas $61.1 \%$ (716) were from rural areas. In this study, among eight divisions, most vulnerable was Dhaka 33.2\% (389) then Khulna 20.4\% (239). $\mathrm{FFH}$ is the major cause of $\mathrm{SCl}$, and the second most common is RTA [Figure 2].

\section{Discussion}

Demographic studies have been conducted but the information from these studies may not be representative of the country. There is no structured health-care delivery system for spinal injuries in Bangladesh. Bangladesh has not had any registry or proper demography study so far. People having spinal injury can go to any hospital of their choice for management. In this study, gender, age, place of habitat, and marital status were taking into consideration as demographic variables. Our study found that $86.2 \%$ ( $n=$ $1010)$ were male and $13.8 \%(n=162)$ were female and this is usual because majority of women work remain in the home while men are exposed to work in outside activities and this result is similar with previously reported in both local ${ }^{[5,13]}$ and global[ ${ }^{[13-15]}$ studies. Most of our SCl patients are young adult injured in the second decade and third decade of life which was different from Hossain et al.'s study where the mean age was 47.44 years $^{[16]}$ and Goel et al.'s study where the average age was $46.65 \pm 16$ years $^{[6]}$ and similar with Ulrich et al.'s study who found the mean age to be 36.1 years. ${ }^{[17]}$ In our country, the main cause of $\mathrm{SCl}$ is the fall from a significant height, whereas in other countries like India, the main cause is RTA. ${ }^{[18]}$ Our study reveals that $\mathrm{SCl}$ is more prone to rural area rather than in urban area about $61.1 \%$ of the respondent was from rural area which is similar to Rahman et al. and Hoque et al. ${ }^{[1,19]}$ Majority of the participants of this study had

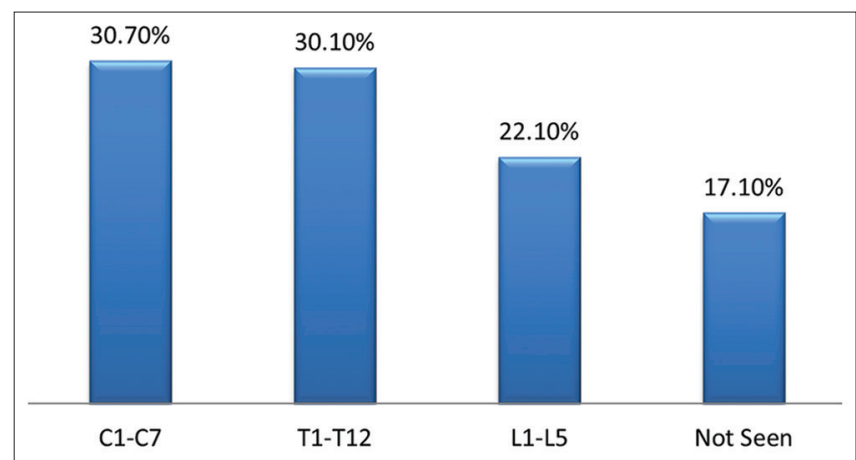

Figure 1: Distribution of skeletal level on admission of the respondents $(n=1172)$ 


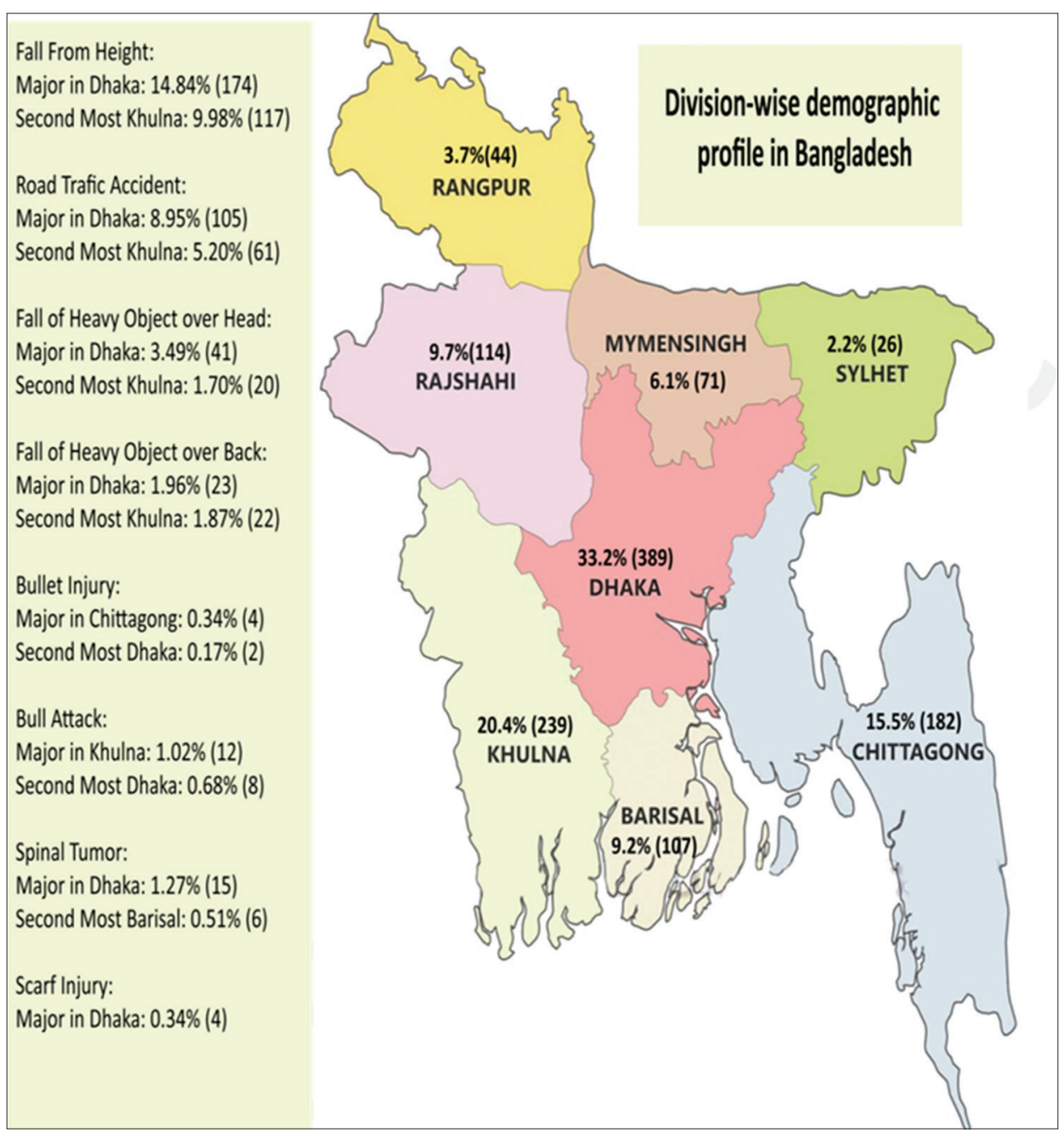

Figure 2: Division-wise distribution of the respondents $(n=1172)$

Table 4: Mode of injury in different studies from Bangladesh literature $(n=1172)$

\begin{tabular}{|c|c|c|c|c|c|c|c|c|}
\hline \multirow[t]{2}{*}{ Author } & \multirow[t]{2}{*}{ Assessment year } & \multicolumn{7}{|c|}{ Cause of injury } \\
\hline & & FFH & RTA & FOH & FOB & Physical assault & Bullet injury & Bull attack \\
\hline Hoque et al. ${ }^{[19]}$ & 1994-1995 & $43 \%$ & $18 \%$ & $20 \%$ & - & - & - & - \\
\hline Abdur Razzak et al..$^{[21]}$ & 1979-1999 & $40.3 \%$ & $14 \%$ & $16 \%$ & $9 \%$ & - & - & - \\
\hline Islam et al..$^{[20]}$ & Jan'2009-June'2009 & $50.5 \%$ & $11.1 \%$ & $15.2 \%$ & $12.1 \%$ & - & - & - \\
\hline Rahman et al..$^{[1]}$ & 2011-2016 & $45.4 \%$ & $25.9 \%$ & $17.8 \%$ & - & - & $1.8 \%$ & \\
\hline Present study & 2012-2014 & $45.8 \%$ & $24.7 \%$ & $9.6 \%$ & $9.0 \%$ & $2 \%$ & $0.7 \%$ & $2 \%$ \\
\hline
\end{tabular}

FFH: Fall from height, FOH: Fall heavy object overhead, FOB: Fall heavy object over back, RTA: Road traffic accident

TP (52.3\%) and the principle cause was the FFH (45.8\%) due to a large number of people connected with fruit harvesting which is important part of our agricultural economy in our country ${ }^{[19]}$ and RTA $(24.7 \%)$ which was found to be consistent with other global literature. ${ }^{[13]}$ Scarf injury $1.1 \%(n=13)$ and bull attack $2 \%(n=24)$ are new cause of SCl where the scarf injury causes a severe type of sufferings for patients with $\mathrm{SCl}$ which was not previously reported. Most of the $\mathrm{SCl}$ patients with complete $\mathrm{SCl}$ evident by category $\mathrm{A}$ in ASIA scale was noted as $60.9 \%$ which is common with Sridharan et al., Hoque et al., and Islam et al. ${ }^{[15,19,20]}$ Most exposed trauma area of $\mathrm{SCl}$ noted as C1-C7 about $30.70 \%(n=359)$ which is common with Hoque et al. ${ }^{[19]}$ The division wise distribution of person with $\mathrm{SCl}$ in our study revealed that $\mathrm{FFH}$ was the major cause (14.84\% [ $n=174])$, while the second most common cause was RTA (8.95\% [ $n=105])$ in Dhaka Division, whereas injury due to bull attack was a major cause of $\mathrm{SCl}$ in Khulna (1.02\%) while bullet injury was major in Chittagong (0.34\%) which are also not reported previously in Bangladesh. 
Table 5: Distribution of ASIA score on admission and during admission of the respondents $(n=1172)$

\begin{tabular}{lcc} 
ASIA & On admission & During discharge \\
\cline { 2 - 2 } & Frequency (\%) & Frequency (\%) \\
\hline A & $714(60.9)$ & $624(53.2)$ \\
B & $230(19.6)$ & $146(12.5)$ \\
C & $133(11.3)$ & $152(13.0)$ \\
D & $86(7.3)$ & $225(19.2)$ \\
E & $9(0.8)$ & $25(2.1)$ \\
\hline
\end{tabular}

ASIA: American Spinal Injury Association

\section{Conclusion}

In many parts of the developing world, $\mathrm{SCl}$ is neglected, socially deprived, and poorly managed. The demographics pattern of $\mathrm{SCl}$ in the developing world is different from the developed world due to extensive research sparse, and data are missing. The data were collected from a tertiary level of rehabilitation center where demographic data were not previously represent and this data mostly represent Bangladeshi population. If it is possible to further exploration like national survey with the expansion of this, data can be the good statistics for government legislation and for prevention of $\mathrm{SCl}$.

\section{Acknowledgments}

The authors would like to thank Md. Ahnaf Al Mukit for his help in data arrangement and Ecommerce Research Project 2020 for their support.

\section{References}

1. Rahman A, Ahmed S, Sultana R, Taoheed F, Andalib A, Arafat SY. Epidemiology of spinal cord injury in Bangladesh: A five year observation from a rehabilitation center. J Spine 2017;6:2.

2. Arafat S, Ahmed S, Ahmed F, Zaman S, Andalib A. Depression in spinal cord injury patients: A cross-sectional observation with PHQ-9 in a rehabilitation center of Bangladesh. J Behav Health 2017;6:1-4. Available from: https:// www.ejmanager.com/mnstemps/57/57-1502452462. pdf?t=1519399648. [Last accessed on 2018 Jan 28].

3. Andalib A, Arafat SM. Does it really matters: Bull attack as a cause of spinal cord injury in Bangladesh? South East Asia J Med Sci 2017;1:3. Available from: http://www. seajournalms.com/index.php/home/article/view/21/20. [Last accessed on 2018 Jan 28].

4. Masud A, Ahmed M, Sultana M, Alam S, Kabir R, Arafat S, et al. Health problems and health care seeking behaviour of Rohingya refugees. J Med Res Innov 2017;1:21-9.

5. Quadir M, Sen K, Sultana M, Ahmed M, Taoheed F, Andalib A, et al. Demography, diagnosis and complications of spinal cord injury patients in a rehabilitation center of Bangladesh. Int J Neurorehabil 2017;4. DOI: 10.4172/23760281.1000244
6. Goel SA, Modi HN, Dave BR, Patel PR, Patel R. Socioeconomic impact of cervical spinal cord injury operated in patients with lower income group. Indian Spine J 2018;1:46-50. Available from: http://www.isjonline.com/temp/ IndianSpineJ1146-4727285_130752.pdf. [Last accessed on 2018 Jan 28].

7. Hossain M, Rahman M, Herbert R, Quadir M, Bowden J, Harvey L. Two-year survival following discharge from hospital after spinal cord injury in Bangladesh. Spinal Cord 2015;54:132-6.

8. Cawley MF, Yarkony GM, Bergman SB. Spinal cord injury rehabilitation. 5. Through the lifespan. Arch Phys Med Rehabil 1997;78 3 Suppl:S73-8. Available from: http:// www.archives-pmr.org/article/S0003-9993(97)90413-5/ pdf. [Last accessed on 2018 Jan 28].

9. Westgren N, Levi R. Quality of life and traumatic spinal cord injury. Arch Phys Med Rehabil 1998;79:1433-9. Available from: http://www.archives-pmr.org/article/S00039993(98)90240-4/pdf. [Last accessed on 2018 Jan 28].

10. Fehlings $M$, Singh $A$, Tetreault $L$, Kalsi-Ryan $S$, Nouri A. Global prevalence and incidence of traumatic spinal cord injury. Clin Epidemiol 2014;6:309.

11. Maynard FM Jr., Bracken MB, Creasey G, Ditunno JF, Donovan $\mathrm{WH}$, Duckeret $\mathrm{TB}$, et al. International standards for neurological and functional classification of spinal cord injury. Spinal Cord 1997;35:266-74. Available from: https://www.sciencedirect.com/ science/article/pii/S1684118210600722. [Last accessed on 2018 Jan 28].

12. Centre for Rehabilitation of the Paralyzed. Annual Report: 2012-2013. Bangladesh. Ability not Disability CRP Printing Press; 2010. Available from: http://www.crp-bangladesh. org/wp-content/uploads/2016/04/Annual-ReportFinal-2012-2013-1.pdf. [Last accessed on 2018 Jan 28].

13. Movaghar R, Sayyah M, Akbari H, Khorramirouz R, Rasouli M, Moradi-Lakeh $M$, et al. Epidemiology of traumatic spinal cord injury in developing countries: A systematic review. Neuroepidemiology 2013;41:65-85.

14. Fyffe D, Deutsch A, Botticello A, Kirshblum S, Ottenbacher K. Racial and ethnic disparities in functioning at discharge and follow-up among patients with motor complete spinal cord injury. Arch Phys Med Rehabil 2014;95:2140-51.

15. Sridharan N, Uvaraj N, Dhanagopal M, Gopinath $N$, Anuswedha A. Epidemiologic evidence of spinal cord injury in Tamil Nadu, India. Int J Res Med Sci 2015;1. DOI: 10.5455/2320-6012.ijrms20150139.

16. Hossain S, Khundkar S. Bacteriological status of pressure sore-a study of 50 cases. Bangladesh J Plast Surg 2013;18:3. Available from: https://www.banglajol.info/index.php/ BDJPS/article/view/15002/10672. [Last accessed on 2018 Jan 28].

17. Ullrich PM, Jensen MP, Loeser JD, Cardenas DD. Pain intensity, pain interference and characteristics of spinal cord injury. Spinal Cord 2008;46:451-5.

18. Chhabra H, Arora M. Demographic profile of traumatic spinal cord injuries admitted at Indian spinal injuries Centre 
with special emphasis on mode of injury: A retrospective study. Spinal Cord 2012;50:745-4. Available from: https:// www.nature.com/articles/sc201245. [Last accessed on 2018 Jan 28].

19. Hoque MF, Grangeon C, Reed K. Spinal cord lesions in Bangladesh: An epidemiological study 1994-1995. Spinal Cord 1999;37:858-61.
20. Islam MS, Hafez MA, Akter M. Characterization of spinal cord lesion in patients attending a specialized rehabilitation center in Bangladesh. Spinal Cord 2011;49:783-6.

21. Razzak A, Helal S, Nuri R, Life Expectancy of Persons with Spinal Cord Injury (SCI) Treated in a Rehabilitation Centre at Dhaka, Bangladesh. Disability, CBR \& Inclusive Development 2011;22:1.DOI:10.5463/DCID.v22i2.34. 